\title{
A Spectrally Selective Window for Hot Climates
}

\author{
M. O. Sid-Ahmed ${ }^{*}$, M. H. Bilal'2, S. G. Babiker ${ }^{3}$ \\ ${ }^{1}$ Department of Physics, Omdurman Ahlia University, Omdurman, Sudan \\ ${ }^{2}$ Department of Physics, Faculty of Education, University of Algadarif, Gadaref, Sudan \\ ${ }^{3}$ Department of Physics, Red Sea University, Port Sudan, Sudan \\ Email: ${ }^{\star}$ mohamedsidahmed5@gmail.com
}

How to cite this paper: Sid-Ahmed, M.O., Bilal, M.H. and Babiker, S.G. (2017) A Spectrally Selective Window for Hot Climates. Journal of Electronics Cooling and Thermal Control, 7, 33-44.

https://doi.org/10.4236/jectc.2017.72004

Received: February 24, 2017

Accepted: May 30, 2017

Published: June 2, 2017

Copyright (c) 2017 by authors and Scientific Research Publishing Inc. This work is licensed under the Creative Commons Attribution International License (CC BY 4.0).

http://creativecommons.org/licenses/by/4.0/

\begin{abstract}
Rigorous coupled-wave analysis has been used to design a glazing for hot climates. The designed glazing is relatively simple and it transmits most of the visible light and reflects most of the infrared radiation. It does not need any external source of energy to control its optical properties. It consists of ITO and four periodic pairs of $\mathrm{Si} / \mathrm{SiO}_{2}$, deposited on a glass sheet. The optimum thicknesses of ITO, $\mathrm{Si}$ and $\mathrm{SiO}_{2}$ are $0.1 \mu \mathrm{m}, 0.15$ and $0.4 \mu \mathrm{m}$, respectively. The glazing acts as an optically selective filter. It transmits about $80 \%$ of the visible light and reflects almost all the infrared radiation. The performance of the glazing is almost independent of the angle of incidence of solar radiation. This makes it suitable for all hours of the day. The fabrication of the glazing and the testing have been performed at the laboratories of the Faculty of Science, University of Witwatersrand, South Africa. Magnetron sputtering technique has been used for the fabrication. ITO, $\mathrm{Si}$ and $\mathrm{SiO}_{2}$ have been used as sputtering targets. The experimental results are almost identical to the simulation results.
\end{abstract}

\section{Keywords}

Smart Windows, Electrochromic Windows, Thermochromic Windows, Hot Climates

\section{Introduction}

Buildings need to provide a pleasant living environment and at the same time to minimize the electricity requirements for lighting and cooling. Recently there is an increasing architectural trend towards more use of glass. Conventional glass, in hot climates, transmits most of the solar infrared radiation. This increases the electricity consumption for cooling.

The household sector in Sudan consumes about $46 \%$ of the total energy consumption [1]. The consumption of electricity for lighting and cooling is about 
$3.5 \times 10^{6} \mathrm{MWh}$ per year.

The shape of a building influences the solar energy that it receives. The solar radiation incident on a building affects the energy requirement for lighting and cooling. By improving the glazing performance of windows, it is possible to reduce the electricity consumption. For more energy saving, the spectral selectivity of the glazing has to be modified. At present, this has been achieved by using eitherelectrochromic or thermotropic devices. The optical properties of these materials are either electrically adjustable or thermally self-adjusting.

Electrochromic windows change light transmission in response to an external applied voltage. The transition from clear to opaque could take 3 - 5 minutes, for a small window [2]. Hong and Chen [3] used nano-Prussian blue analogue/ PEDOT/PSS: composites for a $10 \times 10 \mathrm{~cm}^{2} \mathrm{WO}_{3}$ electrochromic window. A maximum transmittance modulation of $61.6 \%$ at a voltage of $1.6 \mathrm{~V}$ was obtained. Kim and Taya [4] used $\mathrm{V}_{2} \mathrm{O}_{5}$ and poly (3,3-dimethyl-3,4-dihydro- $2 \mathrm{H}$-thieno [3,4-b][1,4]dioxepine) coatings. The window demonstrated electrochemical stability after over 150,000 cyclic switches, and that the response time for a $25 \times 25$ $\mathrm{mm}^{2}$ window was 5 seconds for coloration and 4 seconds for bleaching. Similarly, Kim et al. [5] obtained highelectromatic contrast andoptical cyclic stability, when they used electrochromic windows based on anodic electrochromic polymesitylenes containing 9H-carbazole-9-ethanol moieties. Fernandes et al. [6] used glass/ $\mathrm{ITO} / \mathrm{WO}_{3} /$ electrolyte/ITO/glass layered configuration. That resulted on visible average transmittance variation and optical density change of $41.6 \%$ and $0.39 \%$, respectively. Hee et al. [7] concluded that electrochromic windows are more suitable for applications in residential areas in cold climate regions. Brooke et al. [8] investigated the effect of oxidant on the performance of conductive polymer films. They concluded that the oxidant $\mathrm{Fe}(\mathrm{Tos})_{3}$ produced superior device performance with respect to optical switching, switch speed and optical relaxation. Kim et al. [9] prepared transparent conductive ZnInSnO-Ag-ZnInSnO multilayer films for polymer dispersed liquidcrystal based smart windows. They obtained a lower operating voltage and a higher cutoff rate of infrared light, compared to ITO or ZITO-based smart windows. Khandelwal et al. [10] fabricated electrically switchable broadband infrared reflectors using polymer stabilized cholesteric liquid crystals. They predicted that their reflector can save more than $12 \%$ of energy compared to double glazing window and $9.3 \%$ compared to static infrared reflector. One of the drawbacks of electrochromic windows is their need for external biases to operate. Wang et al. [11] introduced a self-powered window. Aluminum was used to reduce Prussian blue to Prussian white in potassium chloride electrolyte. For self-recovering of the device to the blue appearance, the aluminum and Prussian blue electrodes could be disconnected. Lim et al. [12] studied the performance of tungsten-oxide-based electrochromic window. The results showed that the transmittance of visible light varied from $64 \%$ in the clear state to very low values in the colored state. They also concluded that there is little additional benefit from placing low emissivity coating on the electrochromic window. 
Thermochromic windows switch from a clear state in low temperature to a diffuse reflective state in high temperature. The results of Long et al. [13] indicated that, in hot climate, the use of $\mathrm{VO}_{2}$ window decreases the energy consumption for cooling compared to the case with ordinary window. Zheng et al. [14] designed $\mathrm{TiO}_{2}(\mathrm{R}) / \mathrm{VO}_{2}(\mathrm{M}) / \mathrm{TiO}_{2}(\mathrm{~A})$ multilayer film to work as a smart window with antifogging and self-cleanig functions. Koo et al. [15] fabricated $\mathrm{CeO}_{2}-\mathrm{VO}_{2}$ bilayer to improve the optical properties of $\mathrm{VO}_{2}$ window. The $\mathrm{CeO}_{2}$ was employed as an antireflection layer of the $\mathrm{VO}_{2}$ film. Kamalisarvestani et al. [16] studied the spectral selective properties of thermochromic windows and the effect of doping of $\mathrm{VO}_{2}$ coatings with different dopants. $\mathrm{VO}_{2}$ could be the most promising thermochromic material, but its drawback is the preparation cost and the stability. Batista et al. [17] concluded that tungsten was the most effective dopant on the reduction of the semiconductor-metal transition temperature of $\mathrm{VO}_{2}$. More energy could be saved by using $\mathrm{VO}_{2}$ double window. Long and $\mathrm{Ye}$ [18] suggested that an appropriate phase transition temperature is needed to make the $\mathrm{VO}_{2}$ remains principally in its metallic state with low solar transmittance for summer application and in its semiconductor state with high solar transmittance for winter application. Zhou et al. [19] combined a $\mathrm{VO}_{2}$ thermochromic window with solar cells operated by the scattered radiation from the window. However, the efficiency of the cell was too low to justify the additional cost.

Both electrochromic and thermochromic windows suffer from high cost, low transmission of visible light and slow response time. In tropical regions, the ideal window is the one which transmitsall the visible light to reduce the lighting load, and reflects all the infrared radiation to reduce the cooling load, with $0.78 \mu \mathrm{m}$ cutoff wavelength.

In this paper we studied the potential of usingthin layers of periodic structure as a glazing with spectrally selective properties. The proposed structure is for hot climates. It consists of alternating layers of $\mathrm{Si} / \mathrm{SiO}_{2}$. The performance of the glazing was studied by using rigorous coupled-wave analysis method. The optimized structure was prepared by using magnetron sputtering technique.

\section{Simulation}

Rigorous coupled-wave analysis (RCWA) is formulated in the 1980s by Moharam and Gaylord. It is used for analyzing the diffraction of electromagnetic waves by periodic gratings [20]. RCWA is used in this study to calculate the radiative properties (reflectance and transmittance) of the periodically multilayer surfaces. It analyzes the general diffraction problem by solving Maxwell's equations accurately in each of the three regions (input, multilayer, and output), based on Fourier expansion [21]. In RCWA, diffraction efficiency for each diffraction order is calculated with incident wave properties regardless of feature size, structural profiles, and dielectric function of the materials. The dielectric function of the materials is expressed as, $\varepsilon=(n+i k)^{2}$ where $n$ is the refractive index and $k$ is the extinction coefficient. The accuracy of the solution computed 
depends solely upon the number of terms retained in space harmonic expansion of electromagnetic fields, which corresponds to the diffraction order. Any linearly-polarized incidence can be decomposed into the transverse electric (TE) and transverse magnetic (TM) mode. The normalized electric field of incidence $E_{\text {inc }}$ can be expressed as:

$$
E_{\text {inc }}=\exp \left(i k_{x} x+i k_{z} z-i w t\right)
$$

The electric field in region I (Figure 1) is the superposition of the incident wave and the reflected waves; therefore

$$
E_{1}(x, z)=\exp \left(i k_{x} x+i k_{z} z\right)+\sum_{j} E_{r j} \exp \left(i k_{x j} x-i k_{z j}^{r} z\right)
$$

Similarly, the electric field in region II $\left(E_{I I}\right)$ is the a superposition of all transmitted waves

$$
E_{11}(x, z)=\sum_{j} E_{t j} \exp \left(i k_{x j} x-i k_{z j}^{t} z\right)
$$

The magnetic field in region I and II can be obtained from Maxwell's equation $H$

$$
\begin{aligned}
H_{I}(x, z) & =-\frac{i}{\omega \mu_{0}}\left(\nabla \times E_{I}\right) \\
H_{I I}(x, z) & =-\frac{i}{\omega \mu_{0}}\left(\nabla \times E_{I I}\right)
\end{aligned}
$$

where $\omega$ represents the frequency and $\mu_{0}$ the magnetic permeability of vacuum. The electric and magnetic field components in region M (Figure 1) can be expressed as a Fourier series:

$$
\begin{gathered}
E_{M}(x, z)=\sum \chi_{y j}(z) \exp \left(i k_{x j} x\right) y \\
H_{M}(x, z)=\frac{i k}{\omega \mu_{0}} \sum_{j}\left[\gamma_{x j}(z) x+\gamma_{z j}(z) z\right] \exp \left(i k_{x j} x\right)
\end{gathered}
$$

where $\chi_{y j}$ and $\gamma_{x j}$ are vector components for the jth space-harmonic electric and magnetic field in region $M$ (multilayer region), respectively. Due to the structure periodicity, the relative dielectric function in region $\mathrm{M}, \varepsilon(x)$ and its inverse $\frac{1}{\varepsilon(x)}$, can also be expanded in Fourier series:

$$
\varepsilon(x)=\sum_{p} \varepsilon_{p}^{\text {ord }} \exp \left(i \frac{2 p \pi}{\Lambda} x\right)
$$

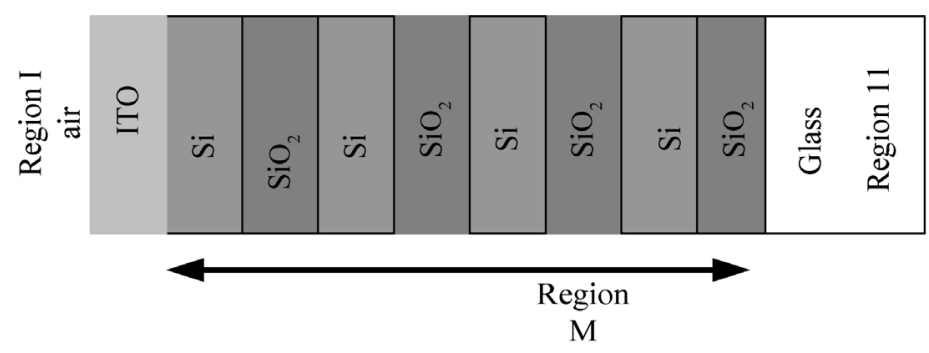

Figure 1. The proposed selective filter components. 


$$
\frac{1}{\varepsilon(x)}=\sum_{p} \varepsilon_{p}^{i n v} \exp \left(i \frac{2 p \pi}{\Lambda} x\right)
$$

where $\varepsilon_{p}^{\text {ord }}$ and $\varepsilon_{p}^{i n v}$ are the jth Fourier coefficient for the ordinary and inverse of $\varepsilon(x)$, respectively.

\section{Optimization of the Thicknesses}

\subsection{Optimization of Si Thickness}

The glazing consists of ITO layer deposited on one-dimensional (ID) four pairs of $\mathrm{Si} / \mathrm{SiO}_{2}$ layers on top ofa $1 \mathrm{~mm}$-glass sheet, Figure 2 . The geometric parameters

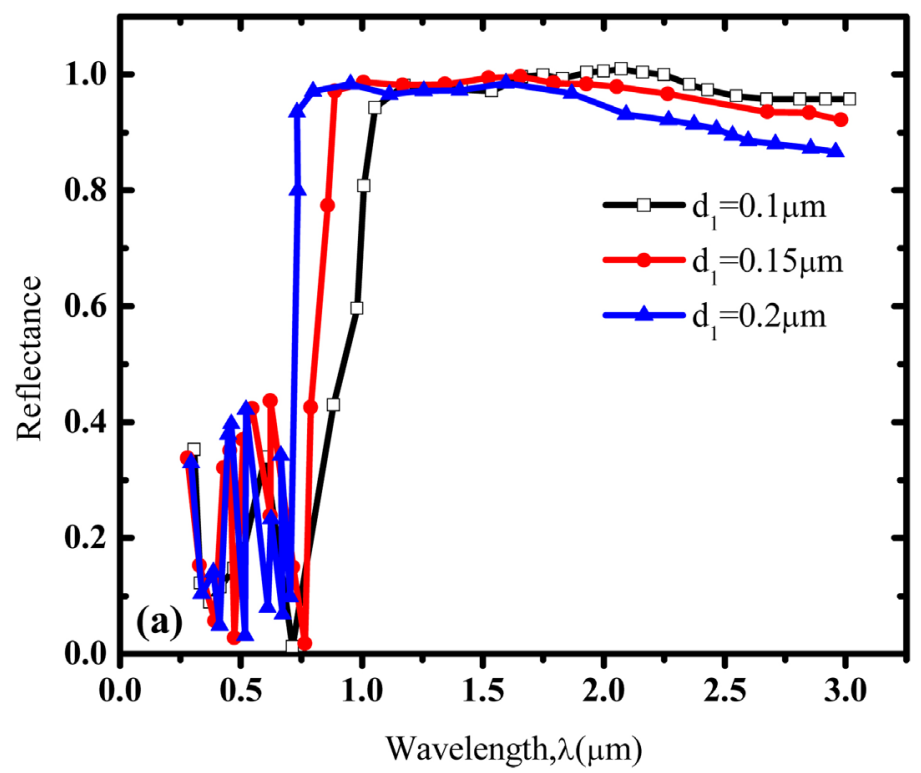

(a)

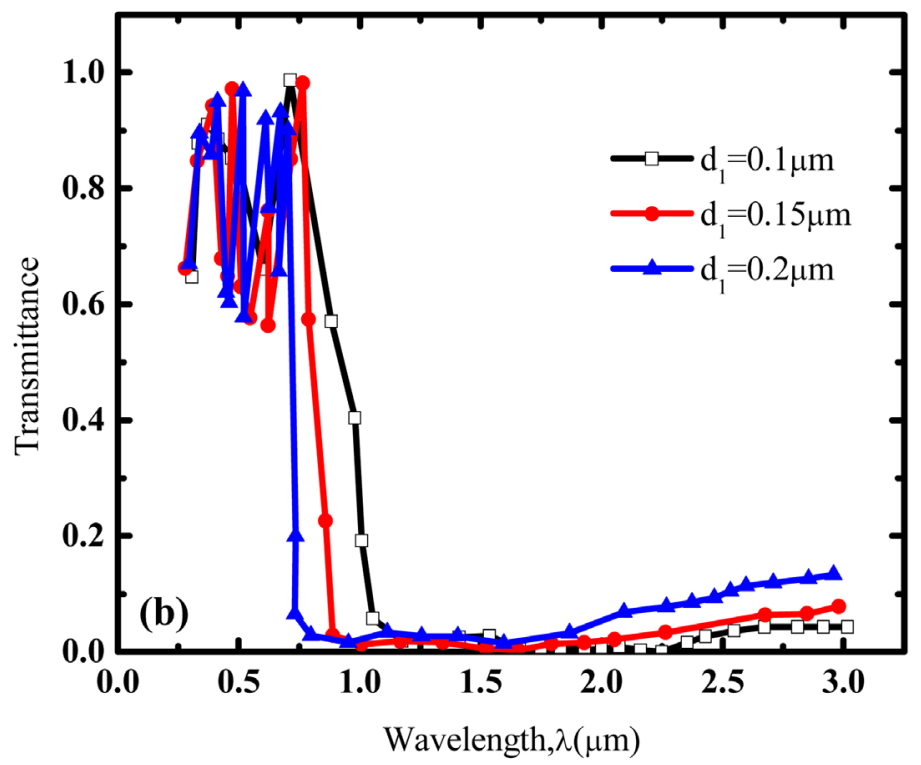

(b)

Figure 2. The proposed selective filter for TM wave with different $d_{1}$ thicknesses. (a) shows the reflectance and (b) the transmittance. 
used to illustrate the wavelength selective filter are the thicknesses of the layers.

The wavelength-dependent dielectric optical constants of ITO, silicon and silicon dioxide were obtained from Ref. [22]. The thickness of ITO was $0.1 \mu \mathrm{m}$ and that of $\mathrm{Si}$ was $d_{1}=0.1,0.15$ and $0.2 \mu \mathrm{m}$. The thickness of $\mathrm{SiO}_{2}$ was fixed at $d_{2}=$ $0.4 \mu \mathrm{m}$. The normal reflectance and transmittance for the proposed selective filter were calculated numerically by using RCWA method in the wavelength range from $0.3 \mu \mathrm{m}$ to $3 \mu \mathrm{m}$.

The normal reflectance and transmittance of the glazing, at normal incidence TM waves, is shown in Figure 2. The results show that the optimum thickness of the $\mathrm{Si}$ is $0.15 \mu \mathrm{m}$. It gives low reflectance (less than $30 \%$ ) for wavelengths less than $0.8 \mu \mathrm{m}$ and reflectance of nearly unity for higher wavelength values. This would transmit most of the visible light (to reduce the lighting load) and reflects nearly all the infrared (to reduce the cooling load).

\subsection{Optimization of $\mathrm{SiO}_{2}$ Thickness}

Figure 3 shows the normal reflectance and transmittance of the glazing for normal incidence TM waves. The thickness of Si was taken to be $0.15 \mu \mathrm{m}$, while that of $\mathrm{SiO}_{2}$ was changed, $d_{2}=(0.2,0.3$ and 0.4$) \mu \mathrm{m}$. The results show that the optimum thickness for $\mathrm{SiO}_{2}$ is $0.4 \mu \mathrm{m}$.

The glazing not only reduces the electricity consumption during daytime, but it also acts as an insulator during the cold nights of winter. It reflects the heat back inside the room. In the desert, the air temperature drops to less than $10^{\circ} \mathrm{C}$ during the night. When the room temperature is about $30^{\circ} \mathrm{C}$, which corresponds to a peak wavelength of about $10 \mu \mathrm{m}$, there would be very little heat loss through the windows, Figure 4.

\subsection{Effect of Angle of Incidence}

The effect of the angle of incidence on the reflectance and transmittance is shown in Figure 5. It is seen that increasing the angle of incidence from $0^{\circ}$ to $60^{\circ}$ makes little difference on the reflectance and transmittance. The glazing seems to be suitable for all seasons and for both direct and diffuse radiation.

\section{Experimental Work}

The fabrication of the window and the measurements of its optical properties were performed at the laboratories of the Faculty of Science, University of Witwatersrand (Wits), South Africa. The filter consists of ITO layer deposited on four pairs of $\mathrm{Si} / \mathrm{SiO}_{2}$ layers on top of a $1 \mathrm{~mm}$-glass sheet. The magnetron sputtering system, shown in Figure 6, was used to deposit a thin film from sputtering targets onto substrate.

The silicon $(\mathrm{S})$ and silicon dioxide $\left(\mathrm{SiO}_{2}\right)$ were used as sputtering targets. The sputtering power and pressure were kept at $100 \mathrm{~W}$ and $140 \mathrm{~W}$ for silicon and silicon dioxide, respectively, and operation pressure at $5.7 \times 10^{-3} \mathrm{~Pa}$. The base vacuum level was $5.3 \times 10^{-3} \mathrm{~Pa}$. The argon gas flow rate was kept at 20 (standard cubic centimeters per minute) and controlled by amass flow meter. The 


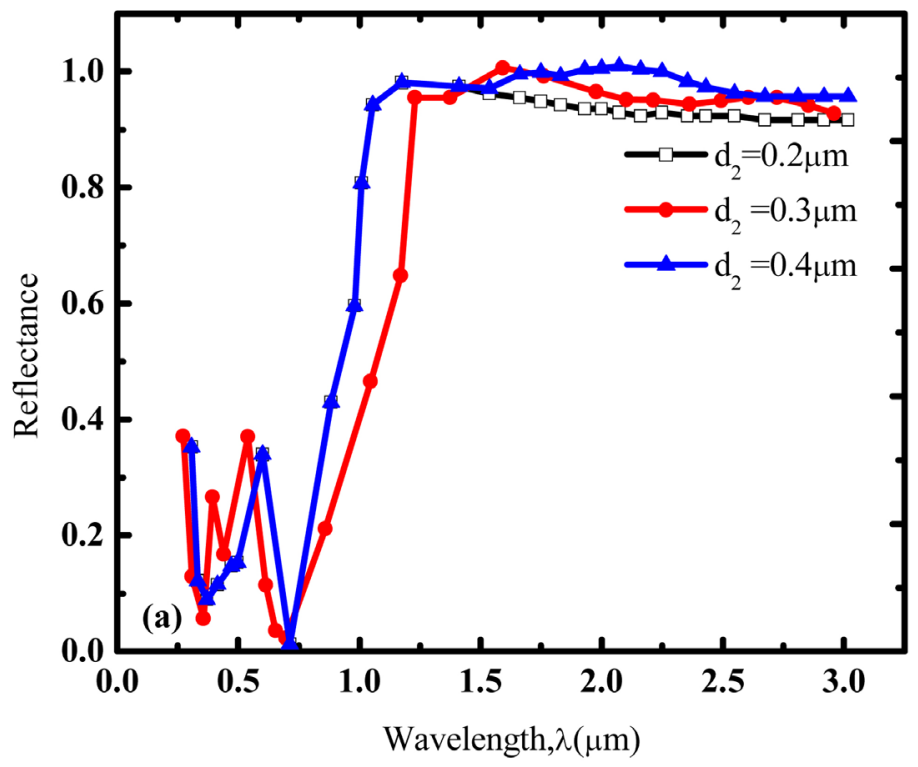

(a)

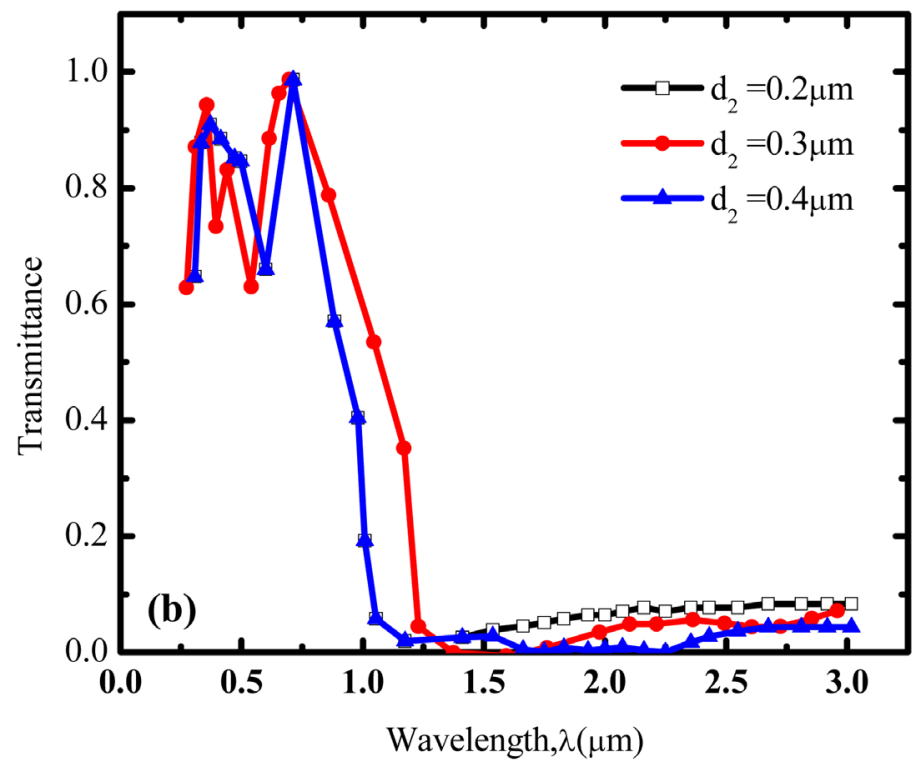

(b)

Figure 3. The glazing with different $\mathrm{SiO}_{2}$ thicknesses. (a) shows the reflectance and (b) the transmittance.

transmittance and reflectance of the filter were measured by a system consisting of a powering system, light source, stepper motor, photo-detectors and analog to digital converter.

\section{Experimental Results}

The measurement of the reflectance and transmittance are shown in Figure 7. The optimum thicknesses of ITO, $\mathrm{Si}$ and $\mathrm{SiO}_{2}$ were found to be $0.1 \mu \mathrm{m}, 0.15$ and o.4 $\mu \mathrm{m}$, respectively. The measurements have also shown that the filter transmits about $78 \%$ of the visible light and reflects nearly all the infrared. These results are almost typical to that obtained by the simulation. 


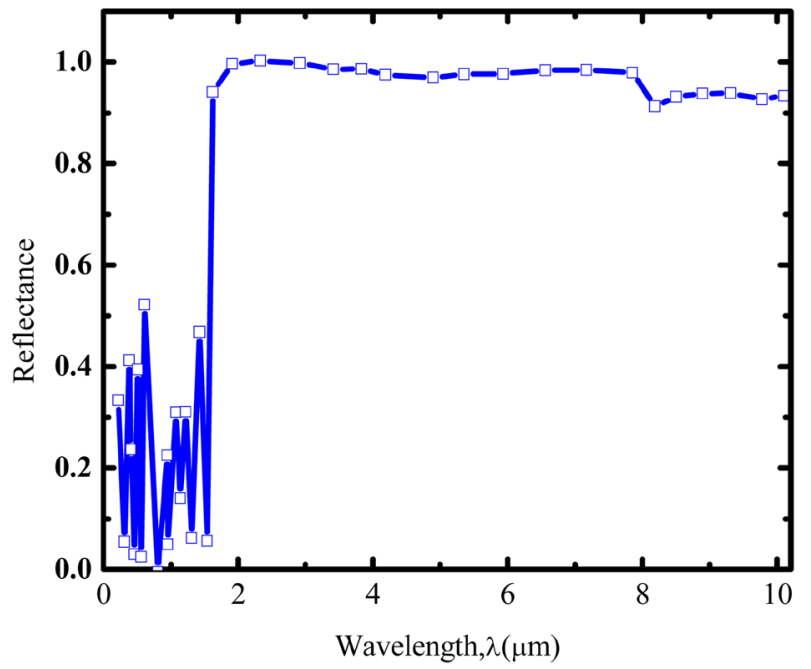

Figure 4. The optical properties of the glazing in the infrared range makes it a potential insulator during the cold nights.

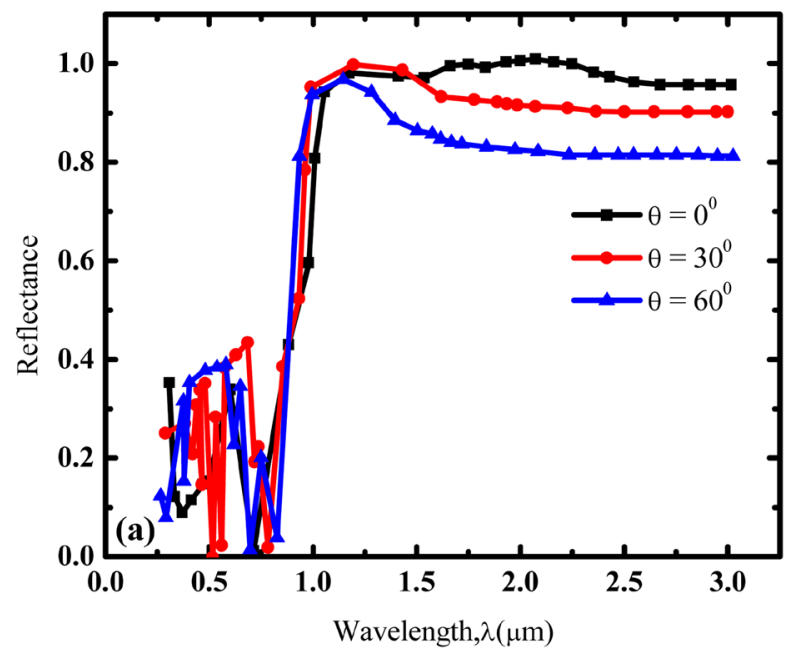

(a)

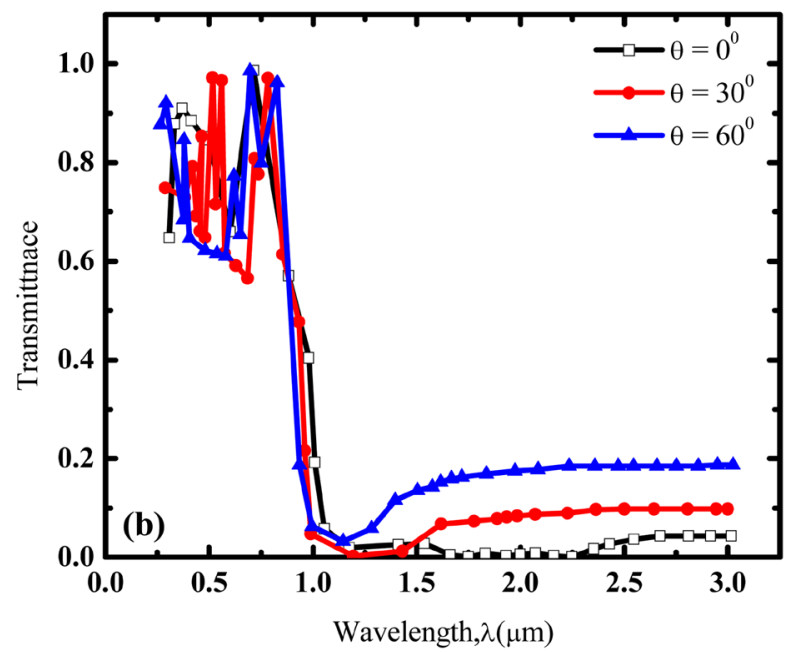

(b)

Figure 5. The performance of the glazing for different incidence angles. (a) reflectance and (b) transmittance. 


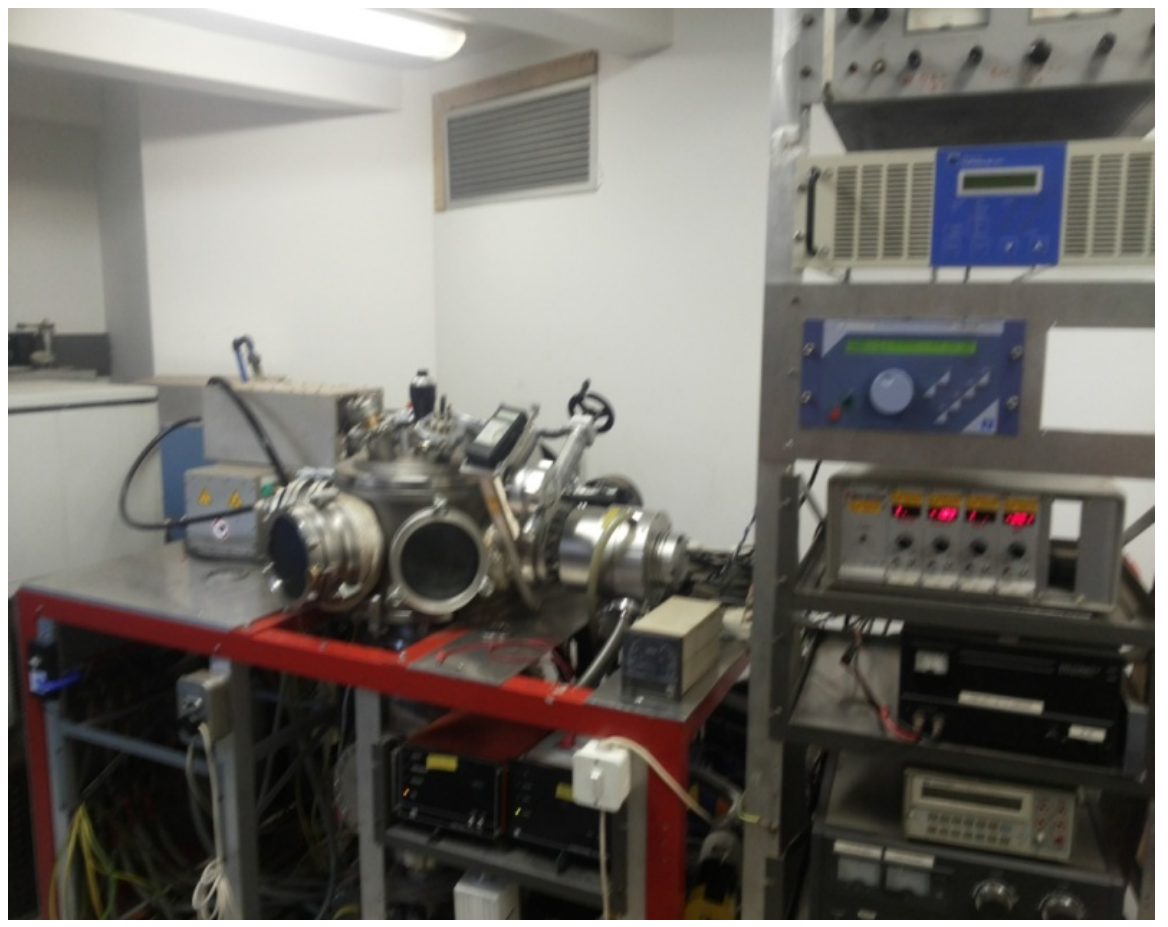

Figure 6. The sputter deposition system at laboratories of the faculty of science, University of Witwatersrand (Wits), South Africa.

\section{Conclusions}

In summary, we have used Rigorous coupled-wave analysis (RCWA) to design a relatively simple and efficient glazing for hot climates. The glazing consisted of ITO and four periodic pairs of $\mathrm{Si} / \mathrm{SiO}_{2}$, deposited on a glass sheet.

RCWA was used to calculate the reflectance and transmittance of the different thicknesses of the layers. The optimum thicknesses of ITO, $\mathrm{Si}$ and $\mathrm{SiO}_{2}$ were found to be (in both simulation and experimental work) $0.1 \mu \mathrm{m}, 0.15 \mu \mathrm{m}$ and 0.4 $\mu \mathrm{m}$, respectively. The glazing transmitted $78 \%$ of the visible light and reflected almost all the infrared radiation from the sun. The optical properties of the glazing hardly depended on the angle of incidence of solar radiation. This makes it ideal for all hours of the day. During the night, in winter, it could act as an insulator to reflect the heat back inside the room. It satisfies the conditions for comfort in both the hot days of summer and the cold nights of winter.

The preparation of the filter and the testing were performed at the laboratories of the Faculty of Science, University of Witwatersrand, South Africa. Indium tin oxide (ITO), silicon ( $\mathrm{Si}$ ) and silicon dioxide $\left(\mathrm{SiO}_{2}\right)$ were used as sputtering targets. The magnetron sputtering system was used to deposit a thin film from sputtering targets onto the substrate.

The experimental results were found to be in good agreement with the simulation results.

It can be concluded that the proposed filter has the advantage that it is relatively simple, efficient, and compared with commercial smart windows, it does not need any external source of energy to control its optical properties. It can be 


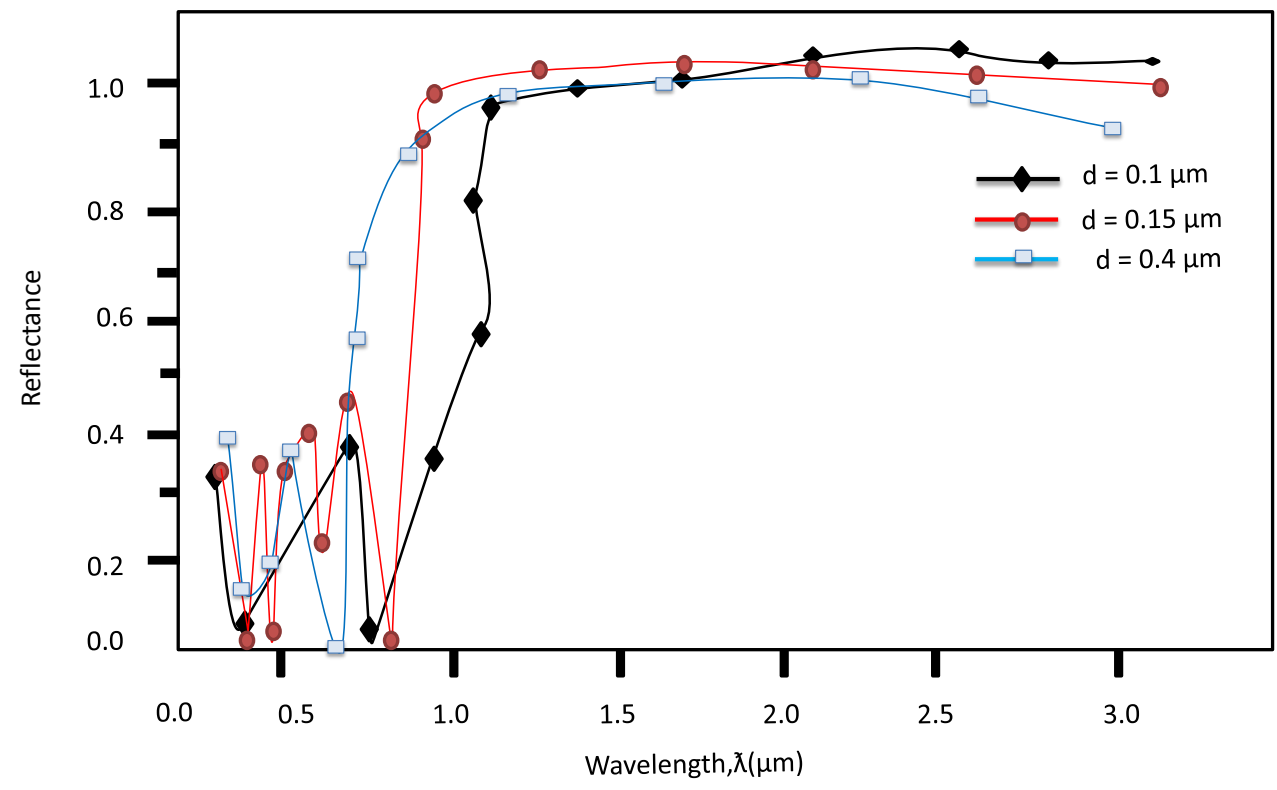

(a)

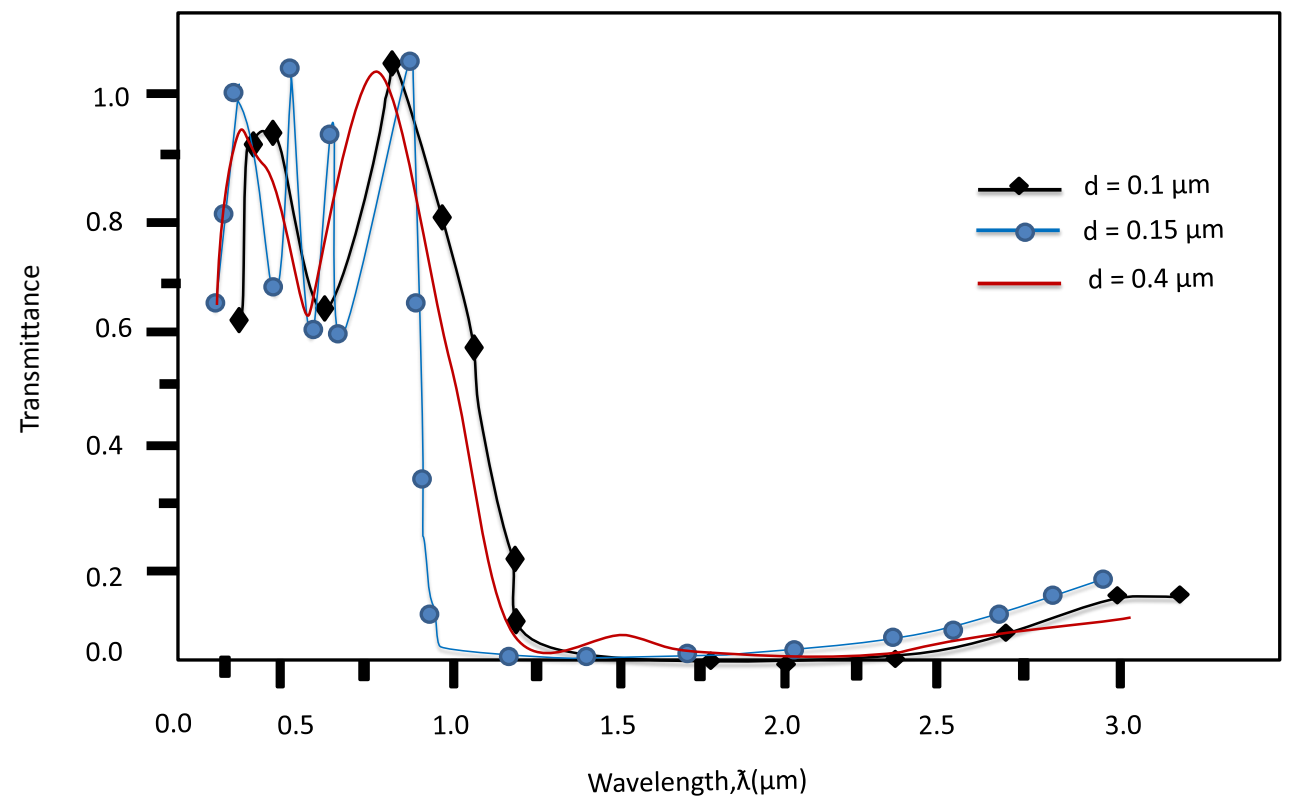

(b)

Figure 7. Reflectance and transmittance of the filter.

used in hot climates in buildings and vehicles.

\section{References}

[1] (2012) Policies and Energy Planning Department, Ministry of Petroleum, Khartoum, Sudan.

[2] Rudolph, S.E., Dieckmann, J. and Brodrick, J. (2009) Technologies for Smart Windows. ASHRAE Journal, 51, 104-106.

[3] Hong, S. and Chen, L. (2012) Nano-Prussian Blue Analogue/PEDOT:PSS Composites for Electrochromic Windows. Solar Energy Materials \& Solar Cells, 104, 64-74.

[4] Kim, S. and Taya, M. (2012) Electrochromic Windows Based on $\mathrm{V}_{2} \mathrm{O}_{5}-\mathrm{TiO}_{2}$ and 
Poly(3,3-Dimethyl-3,4-dihydro-2H-thieno[3,4-b][1,4]dioxepine) Coatings. Solar Energy Materials \& Solar Cells, 107, 225-229.

[5] Kim, S., Kong, X. and Taya, M. (2013) Electrochromic Windows Based on Anodic Electrochromic Polymesitylenes Containing 9H-Carbazole-9-Ethanol Moieties. Solar Energy Materials \& Solar Cells, 117, 183-188.

[6] Fernandes, M., Freitas, V.T., Pereira, S., Fortunato, E., Ferreira, R.A.S., Carlos, L.D., Rego, R. and Bermudez, V. (2014) Green $\mathrm{Li}^{+}-$and $\mathrm{Er}^{3+}$-Doped Poly( $\varepsilon$-Caprolactone)/Siloxane Biohybrid Electrolytes for Smart Electrochromic Windows. Solar Energy Materials \& Solar Cells, 123, 203-210.

[7] Hee, W.J., Alghoul, M.A., Bakhtyar, B., OmKalthum, E., Shameri, M.A., Alrubaih, M.S. and Sopian, K. (2015) The Role of Window Glazing on Daylighting and Energy Saving in Buildings. Renewable and Sustainable Energy Reviews, 42, 323-343.

[8] Brooke, R., Fabretto, M., Vucaj, N., Zuber, K., Switalsaka, E., Reeks, L., Murfy, P. and Evans, D. (2015) Effect of Oxidant on the Performance of Conductive Polymer Films Prepared by Vacuum Vapor Phase Polymerization for Smart Window Applications. Smart Materials and Structures, 24, Article ID: 035016. https://doi.org/10.1088/0964-1726/24/3/035016

[9] Kim, E., Choi, I., Oh, J., Kim, Y., Lee, J., Choi, Y., Cho, J., Kim, Y. and Heo, G. (2014) Transparent Conductive ZnInSnO-Ag-ZnInSnO Multilayer Films for Polymer Dispersed Liquid-Crystal Based Smart Windows. Japanese Journal of Applied Physics, 53, Article ID: 095505. https://doi.org/10.7567/JJAP.53.095505

[10] Khandelwal, H., Loonen, R., Hensen, J., Debije, M. and Schenning, A. (2015) Electrically Switchable Polymer Stabilised Broadband Infrared Reflectors and Their Potential as Smart Windows for Energy Saving in Buildings. Scientific Reports, 5, Article No. 11773. https://doi.org/10.1038/srep11773

[11] Wang, J., Zhang, L., Yu, L., Jiao, Z., Xie, H., Lou, X.W. and Sun, X.W. (2014) Nature Communications, 5921.

[12] Lim, S.H.N., Isidorsson, J., Sun, L., Kwak, B.L. and Anders, A. (2013) Modeling of Optical and Energy Performance of Tungsten-Oxide-Based Electrochromic Windows Including Their Intermediate States. Solar Energy Materials \& Solar Cells, 108, 129-135.

[13] Long, L., Ye, H., Zhang, H. and Gao, Y. (2015) Performance Demonstration and Simulation of Thermochromic Double Glazing in Building Applications. Solar Energy, 120, 55-64.

[14] Zheng, J., Bao, S. and Jin, P. (2015) $\mathrm{TiO}_{2}(\mathrm{R}) / \mathrm{VO}_{2}(\mathrm{M}) / \mathrm{TiO}_{2}(\mathrm{~A})$ Multilayer Film as Smart Window: Combination of Energy-Saving, Antifogging and Self-Cleaning Functions. Nano Energy, 11, 136-145.

[15] Koo, H., Shen, D., Bae, S., Ko, K., Chang, S. and Park, C. (2014) The Effect of $\mathrm{CeO}_{2}$ Antireflection Layer on the Optical Properties of Thermochromic $\mathrm{VO}_{2}$ Film for Smart Window System. Journal of Material Engineering and Performance, 23, 402-407. https://doi.org/10.1007/s11665-013-0740-7

[16] Kamalisarvestani, M., Saidur, R., Mekhilef, S. and Javadi, F.S. (2013) Performance, Materials and Coating Technologies of Thermochromic Thin Films on Smart Windows. Renewable and Sustainable Energy Reviews, 26, 353-364.

[17] Batista, C., Ribero, R. and Teixeira, V. (2011) Synthesis and Characterization of $\mathrm{VO}_{2}$-Based Thermochromic Thin Films for Energy-Efficient Windows. Nanoscale Research Letters, 6, 301. https://doi.org/10.1186/1556-276X-6-301

[18] Long, L. and Ye, H. (2014) Discussion of the Performance Improvement of Thermochromic Smart Glazing Applied in Passive Buildings. Solar Energy, 107, 236-244. 
[19] Zhou, J., Gao, Y., Zhang, Z., Luo, H., Cao, C., Chen, Z., Dai, L. and Liu, X. (2013) $\mathrm{VO}_{2}$ Thermochromic Smart Window for Energy Savings and Generation. Scientific Reports, 3, Article No. 3029. www.nature.com/scietificreports

[20] Moharam, M.G. and Gaylord, K.T. (1981) Rigorous Coupled-Wave Analysis of Planar-Grating Diffraction. Journal of the Optical Society of America, 71, 811-818.

[21] Peng, S. and Morris, M.G. (1995) Efficient Implementation of Rigorous CoupledWave Analysis for Surface-Relief Gratings. Journal of the Optical Society of America $A, 12,1087-1096$.

[22] Palik, D.E. (1985) Handbook of Optical Constants of Solids. Academic Press, San Diego, CA.

Submit or recommend next manuscript to SCIRP and we will provide best service for you:

Accepting pre-submission inquiries through Email, Facebook, LinkedIn, Twitter, etc. A wide selection of journals (inclusive of 9 subjects, more than 200 journals)

Providing 24-hour high-quality service

User-friendly online submission system

Fair and swift peer-review system

Efficient typesetting and proofreading procedure

Display of the result of downloads and visits, as well as the number of cited articles

Maximum dissemination of your research work

Submit your manuscript at: http://papersubmission.scirp.org/

Or contact jectc@scirp.org 